Article

\title{
A Pilot Study into the Association between Oral Health Status and Human Papillomavirus-16 Infection
}

\author{
Charles Xiaohang Sun ${ }^{1,2}$, Nigel Bennett ${ }^{1}$, Peter Tran ${ }^{1,2}$, Kai Dun Tang ${ }^{1}$, Yenkai Lim ${ }^{1}$, \\ Ian Frazer ${ }^{3}$, Lakshman Samaranayake ${ }^{2}$ and Chamindie Punyadeera ${ }^{1, *}$ \\ 1 Institute of Health and Biomedical Innovation, The School of Biomedical Sciences, \\ Queensland University of Technology, 60 Musk Avenue, Kelvin Grove, GPO Box 2434, Brisbane, QLD 4059, \\ Australia; xiaohang.sun@uqconnect.edu.au (C.X.S.); n.bennett@qut.edu.au (N.B.); \\ peter.tran1@uqconnect.edu.au (P.T.); kai.tang@qut.edu.au (K.D.T.); y43.lim@qut.edu.au (Y.L.) \\ 2 School of Dentistry, Faculty of Health and Behavioural Sciences, The University of Queensland, 288 Herston \\ Road, Herston, Brisbane, QLD 4006, Australia; 1.samaranayake@uq.edu.au \\ 3 School of Medicine, Faculty of Medicine and Biomedical Sciences, The University of Queensland, \\ 288 Herston Road, Herston, Brisbane, QLD 4006, Australia; i.frazer@uq.edu.au \\ * Correspondence: chamindie.punyadeera@qut.edu.au; Tel.: +61-7-3138-0830
}

Academic Editors: David Wong and Martin Weber

Received: 21 December 2016; Accepted: 16 February 2017; Published: 1 March 2017

\begin{abstract}
Background: Over the next 20 years, oropharyngeal cancers (OPC) will represent the majority of head and neck cancers (HNCs) in the United States. It is estimated that human papillomavirus (HPV) may account for as much as $70 \%$ to $80 \%$ of OPCs in North America and in certain parts of Europe. It is hence crucial to understand the disease risk factors and natural history of oral HPV infections. We hypothesized that poor oral health (by measures such as poor oral hygiene and periodontal disease) leads to a higher degree of oral HPV-16 infections within a patient cohort from a dental school clinic. This study aims to test this hypothesis and gauge possible disease associations before larger scale studies. Subjects and Methods: 223 participants were recruited in this study from the University of Queensland Dental School clinic. Clinical oral health parameters (such as oral hygiene measures and periodontal disease measurements) have been examined and determined by dental professionals. We have collected oral rinse samples from these volunteers. Results: 10 (4.5\%) out of 223 participants were found to have HPV-16 DNA in their oral rinse samples using NB2 endpoint PCR and Sanger sequencing. Within the HPV-16 DNA positive subjects, $7(70 \%)$ and $3(30 \%)$ were associated with poor oral hygiene and periodontal disease, respectively. Conclusion: Our results show a trend towards a positive correlation between oral HPV-16 infection and poor clinical oral health status.
\end{abstract}

Keywords: human papillomavirus (HPV); oropharyngeal cancer; oral cancer; head and neck cancer; saliva diagnostics; oral rinse; oral health; periodontal health; smoking; alcohol

\section{Introduction}

Over the next 20 years, oropharyngeal cancers (OPC) will represent the majority of head and neck cancers (HNCs) in the United States [1], while oral cavity cancers (OC, mainly non-human papillomavirus (HPV)-16) are increasing in emerging economies [2]. More than half of OPC and OC tumours are diagnosed at an advanced stage [3], and only $50 \%$ of OC patients and $66 \%$ of OPC patients survive beyond 5 years (American Cancer Society, 2015). Furthermore, 30\% of OPC patients develop recurrences and metastases within 2 years [2]. OPC is generally caused by oral or oropharyngeal infection with HPV and, at any given time, approximately $7 \%$ of the population will have an oral or 
oropharyngeal HPV infection [4,5]. The lifetime oral HPV exposure rate is unknown, but an estimated $65 \%-100 \%$ of sexually active adults have been exposed to HPV at any anatomic site (oral, genital, or anal) [6-8]. Men are more likely to have an oral HPV infection than women [4]. It is estimated that HPV may account for as much as $70 \%$ to $80 \%$ of OPCs in North America and in certain parts of Europe [8-10].

HPV is a double-stranded DNA virus, infects basal cells of the epithelium lining and has been documented to cause various epithelial lesions. More than 30 genotypes of mucosotropic HPV have been identified with low-risk types (most common 6,11) being associated with benign lesions and high-risk types (most common 16,18) being associated with malignant conditions (such as cervical malignancy and OPC) [11-13]. HPV-16-driven OPC constitute 90\% of HPV-positive OPC [14]. The aetiology and risk factors of oral and oropharyngeal HPV infection remains controversial; however, past studies have shown that these risk factors include oral sex, multiple sexual partners, poor oral hygiene and immunodeficiency conditions [15-20]. Identifying key risk factors may help to improve disease screening processes to identify high-risk individuals for developing OPC which may lead to OPC prevention and improve disease mortality [21].

The oral cavity and oropharynx are lined with various types of specialised epithelia (i.e., mucosal squamous epithelium) [22]. Due to HPV's known basal cell tropism, it is logical to examine the epithelial components within these regions when studying HPV infections [22]. Previous studies have shown that self-reported poor oral hygiene is an independent risk factor for high-risk HPV infections $[15,23]$. The most common pathology involving oral epithelium is gingivitis-the inflammation of gums. Gingivitis is a non-specific and reversible gingival inflammation in response to oral plaque biofilms [24]. Untreated gingivitis in susceptible patients may progress to periodontitis (the inflammation which features irreversible damage to the gingiva and supporting tissues of the tooth, periodontium) of which the most common type is chronic periodontitis [24].

We hypothesised that poor clinical oral health (measures such as oral hygiene and periodontal disease) leads to a higher degree of oral HPV-16 infections within this dental school patient population. To test this hypothesis, we recruited participants $(n=223)$ with both good and bad oral hygiene and determined their periodontal disease status, as well as other oral health parameters. This is the first study to report clinical oral health parameters examined and evaluated by dental professionals and not self-reported oral health status. We found that oral HPV-16 infection within the Australian Dental study group is $4.5 \%$. Our results demonstrated a positive correlation between oral HPV-16 infection and poor oral health status.

\section{Methods}

\subsection{Participants}

A total of 223 patients attending The University of Queensland School of Dentistry (UQDS) Clinic between October 2014 and October 2015 were recruited as study participants (see Table 1). All participants provided informed consent prior to the study which was approved by the UQ medical research ethics committee (Approval number 2014000862, 22 July 2014), and Queensland University of Technology (QUT) university human research ethics committee (Approval number 1400000641, 11 September 2014). Both approvals were obtained in 2014. The study was performed in accordance with the Declaration of Helsinki.

Participant inclusion criteria included (1) willingness to participate and provide written informed consent; (2) never received HPV vaccination; (3) older than 18 years of age (to exclude disparities due to sexual transmission of HPV) [15,25-27]; (4) no history of cancer and not receiving chemotherapy or radiation therapy, (malignancies and their treatment profoundly affect oral health status and immune status, which may increase HPV infection rates compared to general population rates) [15,25-28]; (5) no history of diabetes mellitus, cardiovascular diseases, blood disorders, xerostomia and any other 
systemic conditions that may affect oral health status) $[15,25-27,29]$; (6) not on current medication; (7) at least 20 teeth in the mouth, to evaluate the effect of periodontal infection on oral HPV infection.

\subsection{Participant Demographics, Lifestyle and Clinical Data}

Participant demographic information included in this study was collected for gender, age and race (see Supplementary Tables S1 and S2). Participant lifestyle factors such as smoking and alcohol consumption status were recorded. Participants' race was classified as Caucasian, Asian, South Asian, Aborigine or Pacific Islander, African, Latino and other ethnicity groups. Participant smoking status was recorded based on the Centre of Disease Control smoking classification as follows: never smoked; former smoker; current daily smoker (1-15 cigarettes/day); current daily smoker (25-34 cigarettes/day); current daily smoker ( $>35$ cigarettes/day); and current non-daily smoker ( $<1$ cigarettes/day) [30]. Participant alcohol consumption status was recorded based on the U.S. Centre for Nutrition Policy and Promotions-Dietary Guidelines for Americans as follows: non-drinker, infrequent drinker ( $<1$ standard drinks / week), regular drinker ( $<1$ standard drink per day, female; $<2$ standard drinks per day, male), regular drinker ( $>1$ standard drink per day, female; $>2$ standard drinks per day, male) [31] All participant demographic and lifestyle measures were confirmed with the participant verbally and recorded at the time of collection.

Participant clinical oral health measures were recorded, including plaque level, supra-gingival calculus level, sub-gingival calculus level (all three parameters were graded as mild-detected on less than $30 \%$ of the total number of teeth, moderate-detected on $30 \%$ to $60 \%$ of the total number of teeth, and severe-detected on more than $60 \%$ of the total number of teeth), periodontal screening record (PSR) (score 0-4, for each of six divided anatomical sextants in the mouth: score $0=$ no bleeding on probing (BOP) and calculus present, no periodontal pocket probing depth greater than $3.5 \mathrm{~mm}$; score $1=$ BOP present, no calculus present, no periodontal pocket probing depth greater than $3.5 \mathrm{~mm}$; score $2=\mathrm{BOP}$ and calculus present, no periodontal pocket probing depth greater than $3.5 \mathrm{~mm}$; score $3=\mathrm{BOP}$ and calculus present, periodontal pocket probing depths greater than $3.5 \mathrm{~mm}$ but less than $5.5 \mathrm{~mm}$, score $4=\mathrm{BOP}$ and calculus present, periodontal pocket probing depths greater than $5.5 \mathrm{~mm}$ ) [32] and decayed, missing and filled teeth (DMFT) number (0-28). All oral health measurements were extracted from participants' most recent oral examination records at the UQDS, at the time of sample collection; the measurement scores were determined by an operating training dentist who conducted the oral examination and the findings were verified by a qualified supervising dentist.

Participants were grouped based on their periodontal disease status. If any of the six PSR scores were greater than 3 , the patient was classified as a periodontal-diseased patient [32]. If none of the six PSR scores were greater than 2, the patient was classified as a non-periodontal-diseased patient [32]. Participants were also grouped based on their oral hygiene status. If any of the plaque and supra/sub-gingival calculus scores were greater than the moderate level, the participant was classified as having poor to fair oral hygiene (as opposed to good to excellent oral hygiene).

\subsection{Salivary Oral Rinse Sample Collection and Processing}

Appropriate environmental controls and blinded blank saline samples were collected at the UQDS to ensure that the sample are not contaminated by HPV-16 virus aerosols. Prior to sample collection, participants were asked to rinse their mouths with water to remove any food debris and other irrelevant material. Participants were then instructed to use $20 \mathrm{~mL}$ of $0.9 \%$ saline to swish and gargle alternatively for $30 \mathrm{~s}$ (alternate every $5 \mathrm{~s}$ ) and spit the sample into a sterile collection tube as per our previous work $[16,33]$. The samples were then transported on dry ice and stored at $-80^{\circ} \mathrm{C}$ at QUT adhering to local storage procedures and protocols, until further processed. Clinical and laboratory staff were double-blinded through a process of sample de-identification in order to reduce the risk of bias. 


\subsection{DNA Extraction from Oral Rinse Samples}

Oral exfoliated cell pellets were resuspended in sterile phosphate-buffered saline (PBS) and DNA was extracted using the QIAmp DNA Mini Kit, Catalog number 51304 (Qiagen, Hilden, Germany) according to the manufacturer's instructions. DNA samples were assessed for purity and quantified on a Nanodrop 1000 Spectrophotometer (Thermo Fisher Scientific, Pittsburgh, PA, USA) (see Figure 1).

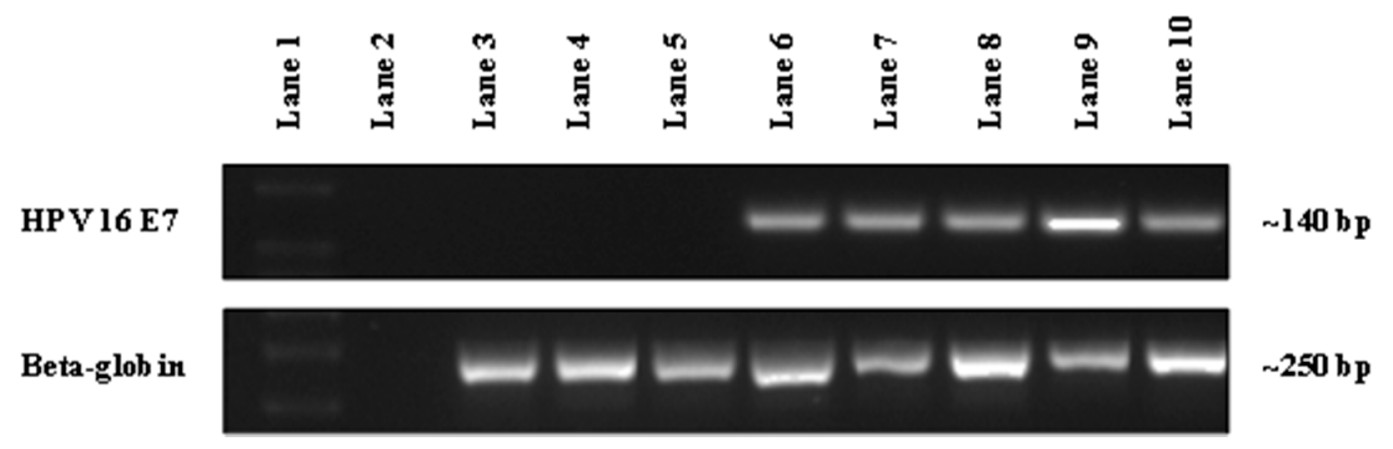

Figure 1. The detection of human papillomavirus (HPV)-16 DNA in patient oral rinse samples from UQ Dental School Clinic by PCR. Representative gel image showing the detection of HPV-16 DNA in patient oral rinse samples using HPV-16 NB2 primers ( 140 bp) with beta-globin used as an internal control ( $250 \mathrm{bp})$. Lane 1 represents DNA Ladder; Lane 2 represents non-template control; Lanes 3-5 (134, 144 and 145) represent the absence of HPV-16 DNA in patient samples; Lanes 6-8 (236, 1338 and 1368) represent the presence of HPV-16 DNA in patient samples and Lane 9 (93VU147T) and 10 (Caski) represent HPV-16 positive cancer cell lines.

\subsection{End-Point PCR Detection and Sequence Confirmation of HPV-16 DNA}

Two rounds of end-point PCR were used to detect HPV-16 DNA extracted from oral rinse samples. HPV-16 specific primers were used to amplify a region of the E7 gene. Human specific primers were used to detect $\beta$-globin as a reference gene to normalise for DNA input and integrity. HPV-16 primer sequences; NB2 Forward primer 5'-AGTGTGACTCTACGCTTCGG-3', NB2 Reverse primer $5^{\prime}$-CTGCAGGATCAGCCATGGTA- $3^{\prime}$. $\beta$-globin primers sequences; Forward primer $5^{\prime}$-CAACTTCATCCACGTTCACC-3' ${ }^{\prime}$, Reverse primer 5'-GAAGAGCCAAGGACAGGTAC-3' The specificity of NB2 primers was ascertained by isolating DNA from the HPV-positive cell line (SCC-2) and amplifying, followed by Sanger sequenceing identification (see Figure 1 and Supplemental Figure S1).

The PCR setup consisted of $50 \mathrm{ng}$ of DNA isolated from oral rinse samples, $1 \mu \mathrm{M}$ of each primer, $1 \times$ Emerald AMP MAX HS PCR Mastermix (Takara Bio, Otsu, Shiga, Japan) in a final volume of $12.5 \mu \mathrm{L}$. PCR cycling consisted of an initial denaturation at $95{ }^{\circ} \mathrm{C}$ for $3 \mathrm{~min}$ followed by 40 cycles of denaturation at $95^{\circ} \mathrm{C}$ for $30 \mathrm{~s}$; annealing at $65^{\circ} \mathrm{C}$ for $30 \mathrm{~s}$ for HPV-16 NB2 primers, or $60^{\circ} \mathrm{C}$ for $\beta$-Globin primers; and extension at $72{ }^{\circ} \mathrm{C}$ for $30 \mathrm{~s}$. A final extension at $72{ }^{\circ} \mathrm{C}$ for $5 \mathrm{~min}$ before cooling to $12{ }^{\circ} \mathrm{C}$ was done. A $1 \mu \mathrm{L}$ volume was transferred to another PCR setup tube and the above reaction conditions were repeated. The entire volume from the second post-PCR samples were subjected to gel electrophoresis at $120 \mathrm{~V}$ for $50 \mathrm{~min}$ in a 3\% agarose gel prepared in TAE buffer (Tris base, acetic acid and EDTA).

PCR amplicons of correct size were excised and gel purified using the QIAquick Gel Extraction Kit, Catalog number 28704 (Qiagen, Hilden, Germany) according to the manufacturer's instructions. Gel purified NB2 amplicons were used in single primer PCR's (NB2 reverse primer) with BigDye ${ }^{\circledR}$ Terminator v3.1 Cycle Sequencing Kit Catalog number: 4337458 (Thermo Fisher Scientific, Waltham, MA, USA). Sanger sequencing clean-up and separation was performed by the Australian Equine Genetics Research Centre, University of Queensland. Specifically, BigDye sequencing reactions were cleaned up with the Agencourt CleanSEQ System (Beckman-Coulter, Brea, CA, USA). Capillary 
electrophoresis and fluorescence detection of cleaned-up reactions were done on either a 3130XL or 3730 Genetic Analyzer (Thermo Fisher Scientific, Waltham, MA, USA). Sanger sequencing results from NB2 amplicons were analysed using the Standard Nucleotide-Basic Local Alignment Search Tool (BLAST) on the National Centre for Biotechnology Information (NCBI) website to confirm HPV-16 homology (see Supplemental Figure S2).

\subsection{Statistical Methods}

In order to examine the potential association between oral health and HPV-16 infection, HPV-16 DNA positivity results were analyzed against patient oral health status and periodontal disease status, as well as other recorded individual parameters (plaque, supra/sub-gingival calculus levels, gender, age, race, smoking and alcohol consumption status), using Fisher's exact test. IBM SPSS v22 (IBM Corp, Armonk, NY, USA) was used as data analysis software. Fisher's exact method was used to obtain $p$-values (exact significance, 1 -sided) for variables with $2 \times 2$ contingency tables (gender, oral health status, periodontal status); for variables with contingency tables greater than $2 \times 2$ (plaque, supra/sub-gingival calculus levels, age, race, smoking and alcohol consumption status), Monte Carlo method (confidence level $99 \%$, sample $=10,000$ ) was used to obtain $p$-values (Monte Carlo significance, 2 -sided). $p$-values less than 0.05 were considered significant. If the $p$ value for a specific variable was significant, post-hoc testing was performed to determine $p$-values for each group within the variable. A significant $p$-value indicated that a specific sub-group within each variable was significantly associated with HPV-16.

\section{Results}

\subsection{Patient Demographics}

Participants $(n=223)$ were recruited from UQDS. Ten $(4.5 \%)$ of these participants were confirmed to be HPV-16 DNA positive using NB2 endpoint PCR followed by Sanger sequencing confirmation.

Participants had a median age of 41 years and were distributed such that 53 participants $(23.8 \%)$ were $18-30$ years old, $106(47.5 \%)$ subjects were $31-50$ years old, $60(26.9 \%)$ subjects were $51-70$ years old, $4(1.8 \%)$ were $71-90$ years old. While more male 137 (61.4\%) than female $86(38.6 \%)$ participants were recruited, the age and gender differences between participants were not statistically significant. Demographically, 166 (78.3\%) participants were identified as Caucasians, 26 (12.3\%) Asians, 10 (4.7\%) South Asians, 4 (1.9\%) Aborigine or Pacific Islanders, 1 (0.5\%) African, $4(1.9 \%)$ Latino and $1(0.5 \%)$ other race.

\subsection{Lifestyle Related Risk Factors/Parameters}

The prevalence of daily smoking amongst participants was 19.0\%, which favorably compared with previous data from a similar UQDS population (22.9\%) [34]. A significant proportion of participants were identified as former smokers (33.0\%). Four out of the ten HPV-16 DNA positive participants did not disclose their smoking status. As such, any association between smoking and HPV-16 DNA infection could not be ascertained.

More than half (52.1\%) of recruited participants were identified as regular consumers of alcohol, with $10.6 \%$ consuming more than one or two standard drinks per day. In total, 35 participants did not disclose their alcohol consumption patterns. A broad variation of alcohol consumption habits was noted amongst both HPV-16 DNA positive and HPV-16 negative participants. Neither frequency nor engagement in infrequent or frequent alcohol consumption were found to be associated with HPV-16 DNA prevalence $(p=0.147)$.

\subsection{Oral Health Parameters}

Almost all participants recruited demonstrated some level of plaque retention (98.6\%). Supra (98.6\%) and sub-gingival (90.0\%) calculus presence was a common clinical finding amongst recruited 
participants. Neither the presence nor severity of these clinical parameters of gingival health was associated with HPV-16 DNA prevalence. Participants were also categorised based on their DMFT score. Of the study cohort, 35.9\% (79) had a low measure of dental decay (past/present), whilst 42.7\% (94) of participants experienced a moderate level of DMFT and 21.4\% (47) of participants recorded a high score of DMFT. Nevertheless, DMFT score was not significantly associated with HPV-16 DNA infection $(p=0.259)$. While periodontal disease status was not significantly associated with the presence of HPV-16 DNA ( $p=0.367)$, a large periodontal disease burden $(40.5 \%)$ was noted within the recruited participants requiring further dental assistance.

Of the $10 \mathrm{HPV}$-positive participants, four patients presented with mild plaque build-up whilst six participants presented with moderate plaque build-up. Based on the aforementioned criteria, three participants presented with good to excellent oral hygiene whilst seven presented with poor to fair oral hygiene. Although the trends concur with our hypothesis, we did not find a statistically significant association between clinical oral health parameters and HPV-16 DNA prevalence status (Table 1).

Table 1. Participant demographic and clinical parameters vs. human papillomavirus (HPV)-16 DNA status using oral rinse samples. DMFT, decayed, missing and filled teeth.

\begin{tabular}{|c|c|c|c|c|}
\hline Variable & $\begin{array}{c}\text { HPV-16 DNA } \\
\text { Positive (\% within } \\
\text { Variable) }\end{array}$ & $\begin{array}{c}\text { HPV-16 DNA } \\
\text { Negative (\% within } \\
\text { Variable) }\end{array}$ & $\begin{array}{l}\text { Total Number } \\
\text { (\% within Total } \\
\text { Population) }\end{array}$ & $p$-Value \\
\hline \multicolumn{5}{|l|}{ Gender } \\
\hline Male & $5(3.6)$ & $132(96.4)$ & 137 (61.4) & \multirow[t]{2}{*}{0.328} \\
\hline Female & $5(5.8)$ & $81(94.2)$ & $86(38.6)$ & \\
\hline \multicolumn{5}{|l|}{ Age } \\
\hline $18-30$ & $1(1.9)$ & $52(98.1)$ & $53(23.8)$ & \multirow{4}{*}{0.130} \\
\hline $31-50$ & $3(2.8)$ & $103(97.2)$ & $106(47.5)$ & \\
\hline $51-70$ & $6(10.0)$ & $54(90.0)$ & $60(26.9)$ & \\
\hline $71-90$ & $0(0)$ & $4(100.00)$ & $4(1.8)$ & \\
\hline \multicolumn{5}{|l|}{ Race } \\
\hline Caucasian & $6(3.6)$ & $160(96.4)$ & $166(78.3)$ & \multirow{7}{*}{1.000} \\
\hline Asian & $0(0)$ & $26(100.0)$ & $26(12.3)$ & \\
\hline South Asian & $0(0)$ & $10(100.0)$ & $10(4.7)$ & \\
\hline Aborigine/Pacific Islander & $0(0)$ & $4(100.0)$ & $4(1.9)$ & \\
\hline African & $0(0)$ & $1(100.0)$ & $1(0.5)$ & \\
\hline Latino & $0(0)$ & $4(100.0)$ & $4(1.9)$ & \\
\hline Other & $0(0)$ & $1(100.0)$ & $1(0.5)$ & \\
\hline \multicolumn{5}{|l|}{ Smoking } \\
\hline Never Smoker & $2(2.1)$ & $95(97.9)$ & $97(45.8)$ & \multirow{7}{*}{0.595} \\
\hline Former Smoker & $4(5.7)$ & $66(94.3)$ & $70(33.0)$ & \\
\hline Current Daily Smoker $<15$ & $0(0)$ & $26(100.00)$ & $26(12.3)$ & \\
\hline Current Daily Smoker 15-24 & $0(0)$ & $12(100.0)$ & $12(5.7)$ & \\
\hline Current Daily Smoker 25-34 & $0(0)$ & $1(100.0)$ & $1(0.5)$ & \\
\hline Current Daily Smoker $>35$ & $0(0)$ & $1(100.0)$ & $1(0.5)$ & \\
\hline Current Non Daily Smoker & $0(0)$ & $5(100.0)$ & $5(2.4)$ & \\
\hline \multicolumn{5}{|l|}{ Alcohol consumption } \\
\hline Non Drinker & $1(1.8)$ & $54(98.2)$ & $55(29.3)$ & \multirow{4}{*}{0.147} \\
\hline Infrequent Drinker & $3(8.6)$ & $32(91.4)$ & $35(18.6)$ & \\
\hline Regular Drinker $(<1 /$ day for $\mathrm{F},<2 /$ day for $\mathrm{M})$ & $1(1.3)$ & $77(98.7)$ & $78(41.5)$ & \\
\hline Regular Drinker ( $>1$ /day for $\mathrm{F},>2 /$ day for $\mathrm{M}$ ) & $1(5.0)$ & $19(95.0)$ & $20(10.6)$ & \\
\hline \multicolumn{5}{|l|}{ Plaque } \\
\hline Nil & $0(0)$ & $3(100.0)$ & $3(1.4)$ & \multirow{4}{*}{0.262} \\
\hline Mild & $4(3.6)$ & $108(96.4)$ & $112(50.9)$ & \\
\hline Moderate & $6(8.1)$ & $68(91.9)$ & $74(33.6)$ & \\
\hline Severe & $0(0)$ & $31(100.0)$ & $31(14.1)$ & \\
\hline \multicolumn{5}{|l|}{ Calculus (Supra-gingival) } \\
\hline Nil & $0(0)$ & $3(100.0)$ & $3(1.4)$ & \multirow{4}{*}{0.182} \\
\hline Mild & $2(1.9)$ & $106(98.1)$ & $108(49.1)$ & \\
\hline Moderate & $6(7.3)$ & $76(92.7)$ & $82(37.3)$ & \\
\hline Severe & $2(7.4)$ & $25(92.6)$ & $27(12.3)$ & \\
\hline \multicolumn{5}{|l|}{ Calculus (Sub-gingival) } \\
\hline Nil & $1(4.5)$ & $21(95.5)$ & $22(10.0)$ & \multirow{4}{*}{0.608} \\
\hline Mild & $3(3.1)$ & $95(96.9)$ & $98(44.5)$ & \\
\hline Moderate & $4(5.6)$ & $68(94.4)$ & $72(32.7)$ & \\
\hline Severe & $2(7.1)$ & $26(92.9)$ & $28(12.7)$ & \\
\hline
\end{tabular}


Table 1. Cont.

\begin{tabular}{lcccc}
\hline \multicolumn{1}{c}{ Variable } & $\begin{array}{c}\text { HPV-16 DNA } \\
\text { Positive (\% within } \\
\text { Variable) }\end{array}$ & $\begin{array}{c}\text { HPV-16 DNA } \\
\text { Negative (\% within } \\
\text { Variable) }\end{array}$ & $\begin{array}{c}\text { Total Number } \\
\text { (\% within Total } \\
\text { Population) }\end{array}$ & $p$-Value \\
\hline $\begin{array}{l}\text { Oral Hygiene } \\
\text { Good to Excellent }\end{array}$ & $3(2.9)$ & $99(97.1)$ & $102(46.4)$ & 0.233 \\
$\quad$ Poor to Fair & $7(5.9)$ & $111(94.1)$ & $118(53.6)$ & \\
\hline DMFT & & & & \\
$0-9$ & $6(7.6)$ & $73(92.4)$ & $79(35.9)$ & 0.259 \\
$10-19$ & $2(2.1)$ & $92(97.9)$ & $94(42.7)$ & \\
$\quad 20-28$ & $2(4.3)$ & $45(95.7)$ & $47(21.4)$ & \\
\hline Periodontal Status & & & & \\
$\quad$ Non-Periodontal-Diseased & $7(5.3)$ & $124(94.7)$ & $131(59.5)$ & 0.367 \\
$\quad$ Periodontal Diseased & $3(3.4)$ & $86(96.6)$ & $89(40.5)$ & \\
\hline
\end{tabular}

\section{Discussion}

This is one of the first HPV studies to use oral health parameters examined and reported by dental professionals. In our study, the prevalence of HPV-16 DNA was found to be $4.5 \%$, a rate comparable to previous studies by Gillison et al. (6.9\%) and Antonsson et al. $(2.3 \%)$ [4,35]. Men showed a lower HPV-16 infection rate (3.6\%) than women (5.8\%). Albeit not being statistically significant, our results showed a positive correlation between oral HPV-16 infection and poor oral hygiene. There was no statistically significant association found between HPV-16 DNA detection and socio-demographic or clinical oral health parameters.

A range of potential risk factors for oral HPV-16 infections, such as close contact with HPV-positive parents during early childhood [12], or maternal cervical/vaginal contact with a HPV-positive mother during birth [36] have been proposed. In addition, it is widely accepted that oral sexual activities are an established risk factor for HPV-16 infection [15,25-28,37-39]. In the current study, no social history and/or history of oral sex activities were collated. In a previous study, Bui et al. [15] observed an association between self-reported poor oral health and the risk of HPV-16 infection. An important differentiation factor between our study and the latter work is the distinction between clinically measured oral health parameters in our study as opposed to self-reported subjective oral health measures reported by Bui et al. The latter researchers also found self-reported oral health status to be an independent risk factor for oral HPV infection (OR $=1.55 ; 95 \% \mathrm{CI}, 1.15-2.09)$. Similar trends of odds ratios were observed in our study between clinical oral hygiene status and HPV-16 infections $(\mathrm{OR}=2.08 ; 95 \% \mathrm{CI}, 0.52-8.27)$, though the wide confidence interval reflects the relatively low incidence of infection, and smaller sample size, in the present study.

It has been suggested by Tezal et al. that oral HPV infections may modify periodontal disease, and interact in a complex manner $[28,36,40]$. It has been proposed that instead of periodontal infections creating a suitable niche for oral HPV infections, it is also possible that oral HPV infection will exacerbate periodontal diseases [28,36]. Although gingivitis is an essential precursor for chronic periodontitis, not all gingivitis patients progress to chronic periodontitis, irrespective of the extent and duration of disease [28]. Multiple theories have been proposed for this two-way process of disease transformation, apart from the commonly accepted theory that periodontal patients elicit a different immune response due to their genetic predisposition [28,41]. One of these is that multi-organism synergy may play a role in the disease transformation process [28]. Virus-induced immunological responses may cause an imbalance between the host and pathogen, resulting in gingivitis-periodontitis transformation [28,41]. Additionally, HPV infection causes a cellular defect known as koilocytosis [39], whereby fragile defective cells may be more prone to potential periodontal breakdown [39,41]. Therefore, a model of the interaction between the two disease entities may be much more complex than hitherto envisioned and remains to be elucidated.

The major limitations in our study are the sample size. It is likely insufficient to detect a significant increase in HPV-16 infection associated with poor oral hygiene, as a minimum sample size of 150 per group would have been required for this purpose (power $=0.90, \alpha=0.05$, anticipated detection rate 
in good oral hygiene group $=0.02$ ). Another important consideration regarding the participants of this study is that the majority are patients who required treatment due to active oral disease within a university clinic setting. Consequently, the prevalence of poor oral hygiene and dental and periodontal infection in the study participants was not necessarily reflective of the general population in Australia.

\section{Conclusions}

In our pilot study population, the prevalence of HPV-16 DNA was found to be $4.5 \%$. The results from this study highlight a positive correlation between oral HPV infection and poor hygiene, which has previously been documented to be an independent risk factor of HPV infection. Future studies with a larger study population (including healthy controls with premalignant disease as well as people with chronic inflammation) with active clinical oral health parameters may yield significant results. It has been advocated that general dental practitioners should advise patients about oral sexual behavior and HPV infection risk. However, for this practice to become part of routine dental consultative practices, many cultural and social hurdles need to be overcome [42] and clear evidence linking poor oral health to HPV infection needs to be presented.

Supplementary Materials: The following are available online at www.mdpi.com/2075-4418/07/1/11/s1.

Acknowledgments: This study was supported by the Garnett Passé and Rodney Williams Memorial Foundation and the Queensland Centre for Head and Neck Cancer funded by Atlantic Philanthropies, the Queensland Government, and the Princess Alexandra Hospital. Chamindie Punyadeera is funded on a QUT VC Fellowship. We also thank the clinical staff at the UQ Dental School for their support. We would also like to thank Dimitrios Vagenas for statistical assistance.

Author Contributions: Author Charles Xiaohang Sun contributed to study concepts, study design, data acquisition, statistical analysis, manuscript preparation, editing and review. Author Nigel Bennett was responsible for data acquisition, quality control of data and algorithms, data analysis and interpretation, statistical analysis. Author Peter Tran contributed to study concepts, study design, data acquisition, manuscript preparation. Author Kai Dun Tang contributed to data acquisition, quality control of data and algorithms, data analysis and interpretation. Author Yenkai Lim contributed to quality control of data and algorithms, data analysis and interpretation. Author Ian Frazer contributed to study concept, study design, manuscript preparation, editing and review. Author Lakshman Samaranayake contributed to study concept, study design, manuscript preparation, editing and review. Author Chamindie Punyadeera contributed to study concepts, study design, data acquisition, quality control of data and algorithms statistical analysis, manuscript preparation, editing and review.

Conflicts of Interest: The authors declare no conflict of interest.

\section{Abbreviations}

$\begin{array}{ll}\text { HPV } & \text { human papillomavirus } \\ \text { OPC } & \text { oropharyngeal cancer } \\ \text { HNC } & \text { head and neck cancers } \\ \text { OC } & \text { oral cavity cancer } \\ \text { BOP } & \text { bleeding on probing } \\ \text { PSR } & \text { periodontal screening record } \\ \text { DMFT } & \text { decayed, missing and filled teeth index }\end{array}$

\section{References}

1. Chaturvedi, A.K.; Engels, E.A.; Pfeiffer, R.M.; Hernandez, B.Y.; Xiao, W.; Kim, E.; Jiang, B.; Goodman, M.T.; Sibug-Saber, M.; Cozen, W.; et al. Human papillomavirus and rising oropharyngeal cancer incidence in the United States. J. Clin. Oncol. 2011, 29, 4294-4301. [CrossRef] [PubMed]

2. Chaturvedi, A.K.; Engels, E.A.; Anderson, W.F.; Gillison, M.L. Incidence trends for human papillomavirus-related and -unrelated oral squamous cell carcinomas in the United States. J. Clin. Oncol. 2008, 26, 612-619. [CrossRef] [PubMed]

3. Menzin, J.; Lines, L.M.; Manning, L.N. The economics of squamous cell carcinoma of the head and neck. Curr. Opin. Otolaryngol. Head Neck Surg. 2007, 15, 68-73. [CrossRef] [PubMed] 
4. Gillison, M.L.; Broutian, T.; Pickard, R.K.; Tong, Z.Y.; Xiao, W.; Kahle, L.; Graubard, B.I.; Chaturvedi, A.K. Prevalence of oral HPV infection in the United States, 2009-2010. JAMA 2012, 307, 693-703. [CrossRef] [PubMed]

5. Pickard, R.K.; Xiao, W.; Broutian, T.R.; He, X.; Gillison, M.L. The prevalence and incidence of oral human papillomavirus infection among young men and women, aged 18-30 years. Sex. Transm. Dis. 2012, 39, 559-566. [CrossRef] [PubMed]

6. Hariri, S.; Unger, E.R.; Sternberg, M.; Dunne, E.F.; Swan, D.; Patel, S.; Markowitz, L.E. Prevalence of genital human papillomavirus among females in the United States, the National Health And Nutrition Examination Survey, 2003-2006. J. Infect. Dis. 2011, 204, 566-573. [CrossRef] [PubMed]

7. Giuliano, A.R.; Lazcano-Ponce, E.; Villa, L.L.; Flores, R.; Salmeron, J.; Lee, J.H.; Papenfuss, M.R.; Abrahamsen, M.; Jolles, E.; Nielson, C.M.; et al. The human papillomavirus infection in men study: Human papillomavirus prevalence and type distribution among men residing in Brazil, Mexico, and the United States. Cancer Epidemiol. Biomark. Prev. 2008, 17, 2036-2043. [CrossRef] [PubMed]

8. Sturgis, E.M.; Ang, K.K. The epidemic of HPV-associated oropharyngeal cancer is here: Is it time to change our treatment paradigms? J. Natl. Compr. Cancer Netw. 2011, 9, 665-673.

9. Boscolo-Rizzo, P.; Del Mistro, A.; Bussu, F.; Lupato, V.; Baboci, L.; Almadori, G.; Da Mosto, M.C.; Paludetti, G. New insights into human papillomavirus-associated head and neck squamous cell carcinoma. Acta Otorhinolaryngol. Ital. 2013, 33, 77-87. [PubMed]

10. Zaravinos, A. An updated overview of HPV-associated head and neck carcinomas. Oncotarget 2014, 5, 3956-3969. [CrossRef] [PubMed]

11. Syrjänen, S.; Lodi, G.; von Bültzingslöwen, I.; Aliko, A.; Arduino, P.; Campisi, G.; Challacombe, S.; Ficarra, G.; Flaitz, C.; Zhou, H.; et al. Human papillomaviruses in oral carcinoma and oral potentially malignant disorders: A systematic review. Oral Dis. 2011, 17, 58-72. [CrossRef] [PubMed]

12. Flake, C.; Arafa, J.; Hall, A.; Ence, E.; Howard, K.; Kingsley, K. Screening and detection of human papillomavirus (HPV) high-risk strains HPV16 and HPV18 in saliva samples from subjects under 18 years old in Nevada: A pilot study. BMC Oral Health 2012, 12, 43. [CrossRef] [PubMed]

13. Bosch, F.X.; Broker, T.R.; Forman, D.; Moscicki, A.-B.; Gillison, M.L.; Doorbar, J.; Stern, P.L.; Stanley, M.; Arbyn, M.; Poljak, M.; et al. Comprehensive Control of Human Papillomavirus Infections and Related Diseases. Vaccine 2013, 31, H1-H31. [CrossRef] [PubMed]

14. Kreimer, A.R.; Clifford, G.M.; Boyle, P.; Franceschi, S. Human papillomavirus types in head and neck squamous cell carcinomas worldwide: A systematic review. Cancer Epidemiol. Biomark. 2005, 14, 467-475. [CrossRef] [PubMed]

15. Bui, T.C.; Markham, C.M.; Ross, M.W.; Mullen, P.D. Examining the association between oral health and oral HPV infection. Cancer Prev. Res. 2013, 6, 917-924. [CrossRef] [PubMed]

16. Chai, R.C.; Lambie, D.; Verma, M.; Punyadeera, C. Current trends in the etiology and diagnosis of HPV-related head and neck cancers. Cancer Med. 2015, 4, 596-607. [CrossRef]

17. Chai, R.C.; Lim, Y.; Frazer, I.H.; Wan, Y.; Perry, C.; Jones, L.; Lambie, D.; Punyadeera, C. A pilot study to compare the detection of HPV-16 biomarkers in salivary oral rinses with tumour p16(INK4a) expression in head and neck squamous cell carcinoma patients. BMC Cancer 2016, 16, 178. [CrossRef] [PubMed]

18. Salazar, C.; Calvopina, D.; Punyadeera, C. miRNAs in human papilloma virus associated oral and oropharyngeal squamous cell carcinomas. Expert Rev. Mol. Diagn. 2014, 14, 1033-1040. [CrossRef] [PubMed]

19. Shigeishi, H.; Sugiyama, M. Risk Factors for Oral Human Papillomavirus Infection in Healthy Individuals: A Systematic Review and Meta-Analysis. J. Clin. Med. Res. 2016, 8, 721-729. [CrossRef] [PubMed]

20. Woods, R.S.R.; O’Regan, E.M.; Kennedy, S.; Martin, C.; O’Leary, J.J.; Timon, C. Role of human papillomavirus in oropharyngeal squamous cell carcinoma: A review. World J. Clin. Cases 2014, 2, 172-193. [PubMed]

21. Bui, T.C.; Tran, L.T.; Markham, C.M.; Huynh, T.T.; Tran, L.T.; Pham, V.T.; Tran, Q.M.; Hoang, N.H.; Hwang, L.Y.; Sturgis, E.M. Self-reported Oral Health, Oral Hygiene, and Oral HPV Infection in At-Risk Women in Ho Chi Minh City, Vietnam. Oral Surg. Oral Med. Oral Pathol. Oral Radiol. 2015, 120, $34-42$. [CrossRef] [PubMed]

22. Jacob, A.; Janam, P.; Vijayamma, J.M.B. Prevalence of human papilloma virus in marginal periodontium and its association with periodontitis: A cross sectional study. J. Indian Soc. Periodontol. 2014, 18, 447-450. [CrossRef] [PubMed] 
23. Mazul, A.L.; Taylor, J.M.; Divaris, K.; Weissler, M.C.; Brennan, P.; Anantharaman, D.; Abedi-Ardekani, B.; Olshan, A.F.; Zevallos, J.P. Oral health and human papillomavirus-associated head and neck squamous cell carcinoma. Cancer 2017, 123, 71-80. [CrossRef] [PubMed]

24. Australian Research Centre for Population Oral Health. Periodontal diseases in the Australian adult population. Aust. Dent. J. 2009, 54, 390-393.

25. Ciarrocca, K.; Jackson, L.L.; de Rossi, S.S. Human papillomavirus: The fundamentals of HPV for oral health care providers. J. Calif. Dent. Assoc. 2013, 41, 349-355. [PubMed]

26. Cleveland, J.L.; Junger, M.L.; Saraiya, M.; Markowitz, L.E.; Dunne, E.F.; Epstein, J.B. The connection between human papillomavirus and oropharyngeal squamous cell carcinomas in the United States: Implications for dentistry. J. Am. Dent. Assoc. 2011, 142, 915-924. [CrossRef] [PubMed]

27. Sanders, A.E.; Slade, G.D.; Patton, L.L. National prevalence of oral HPV infection and related risk factors in the U.S. adult population. Oral Dis. 2012, 18, 430-441. [CrossRef] [PubMed]

28. Tezal, M.; Sullivan, M.A.; Stoler, D.L.; Melendy, T.; Hyland, A.; Smaldino, P.J.; Rigual, N.R.; Loree, T.R. Chronic periodontitis-human papillomavirus synergy in base of tongue cancers. Arch. Otolaryngol. Head Neck Surg. 2009, 135, 391-396. [PubMed]

29. Cullinan, M.P.; Ford, P.J.; Seymour, G.J. Periodontal disease and systemic health: Current status. Aust. Dent. J. 2009, 54 (Suppl. 1), S62-S69. [CrossRef] [PubMed]

30. Schoenborn, C.A.; Adams, P.F.; Peregoy, J.A. Health behaviors of adults: United States, $2008-2010$. Vital Health Stat. 2013, 257, 1-184.

31. Dietary Guidelines for Americans; U.S. Government Printing Office: Washington, DC, USA, 2010.

32. Preshaw, P.M. Detection and diagnosis of periodontal conditions amenable to prevention. BMC Oral Health 2015, 15 (Suppl. 1), S5. [CrossRef] [PubMed]

33. Samaranayake, L.P.; MacFarlane, T.W.; Lamey, P.J.; Ferguson, M.M. A comparison of oral rinse and imprint sampling techniques for the detection of yeast, coliform and Staphylococcus aureus carriage in the oral cavity. J. Oral Pathol. 1986, 15, 386-388. [CrossRef] [PubMed]

34. Ford, P.J.; Tran, P.; Cockburn, N.; Keen, B.; Kavanagh, D.J.; Gartner, C. Survey of dental clinic patients: Smoking and preferences for cessation support. Aust. Dent. J. 2016, 61, 219-226. [CrossRef] [PubMed]

35. Antonsson, A.; Cornford, M.; Perry, S.; Davis, M.; Dunne, M.P.; Whiteman, D.C. Prevalence and risk factors for oral HPV infection in young Australians. PLoS ONE 2014, 9, e91761. [CrossRef] [PubMed]

36. Tezal, M. Interaction between chronic inflammation and oral HPV infection in the etiology of head and neck cancers. Int. J. Otolaryngol. 2012, 2012, 575242. [CrossRef] [PubMed]

37. D’Souza, G.; Kreimer, A.R.; Viscidi, R.; Pawlita, M.; Fakhry, C.; Koch, W.M.; Westra, W.H.; Gillison, M.L. Case-control study of human papillomavirus and oropharyngeal cancer. N. Engl. J. Med. 2007, 356, 1944-1956. [CrossRef] [PubMed]

38. Horewicz, V.V.; Feres, M.; Rapp, G.E.; Yasuda, V.; Cury, P.R. Human papillomavirus-16 prevalence in gingival tissue and its association with periodontal destruction: A case-control study. J. Periodontol. 2010, 81, 562-568. [CrossRef] [PubMed]

39. Hormia, M.; Willberg, J.; Ruokonen, H.; Syrjänen, S. Marginal periodontium as a potential reservoir of human papillomavirus in oral mucosa. J. Periodontol. 2005, 76, 358-363. [CrossRef]

40. Tezal, M.; Sullivan, M.A.; Hyland, A.; Marshall, J.R.; Stoler, D.; Reid, M.E.; Loree, T.R.; Rigual, N.R.; Merzianu, M.; Hauck, L.; et al. Chronic periodontitis and the incidence of head and neck squamous cell carcinoma. Cancer Epidemiol. Biomark. Prev. 2009, 18, 2406-2412. [CrossRef] [PubMed]

41. Parra, B.; Slots, J. Detection of human viruses in periodontal pockets using polymerase chain reaction. Oral Microbiol. Immunol. 1996, 11, 289-293. [CrossRef] [PubMed]

42. Daley, E.; DeBate, R.; Dodd, V.; Dyer, K.; Fuhrmann, H.; Helmy, H.; Smith, S.A. Exploring awareness, attitudes, and perceived role among oral health providers regarding HPV-related oral cancers. J. Public Health Dent. 2011, 71, 136-142. [CrossRef] [PubMed]

(c) 2017 by the authors. Licensee MDPI, Basel, Switzerland. This article is an open access article distributed under the terms and conditions of the Creative Commons Attribution (CC BY) license (http://creativecommons.org/licenses/by/4.0/). 